\title{
The prevalence and associated factors on timely initiation of breastfeeding among mothers of children age less than 12 months in Wolaita Sodo City, Wolaita, Ethiopia.
}

Daniel Baza Gargamo ( $\sim$ danielbaza9@gmail.com )

Wolaita Sodo University

Kasahun Taffesse Hidoto

Wolaita Sodo University

Temesgen Lera Abiso

Powiatowy Szpital Specjalistyczny Stalowa Wola

\section{Research}

Keywords: timely initiation of breastfeeding, infants from birth to 12 months, Wolaita Sodo City, Ethiopia

Posted Date: January 16th, 2020

DOl: https://doi.org/10.21203/rs.2.21035/v1

License: (c) (1) This work is licensed under a Creative Commons Attribution 4.0 International License.

Read Full License 


\section{Abstract}

Background : timely initiation of breastfeeding, also known as early initiation, is the provision of a mothers own breast milk to her infant within one hour of birth. In Ethiopia, there is a considerable variation in the timely initiation of breastfeeding practices among different regions. The objective of this study was to assess the prevalence of timely initiation of breastfeeding and associated factors among mothers of infants less than 12 months old in Wolaita Sodo City, Wolaita, Ethiopia.

Methods: Community based cross-sectional study design was conducted. Multi stage sampling procedure was used. The study period was from January to March 2019. Data was collected by interviewer administered pretested questionnaire. Both bivariate and multivariate analysis was employed and adjusted odds ratio (AOR) was used to declare statistical significance at P-value of less than 0.05 .

Results: A total of 383 mothers with children less than 12 months age were included in the study making the response rate of $97.7 \%$. The prevalence of timely initiation of breast feeding within an hour was $80.2 \%$. Being male child was 3.39 times AOR: $3.39,95 \% \mathrm{Cl}: 3.39(1.49,7.71)$ more likely to be timely initiated breast feeding within an hour than those who are female children. Those children who live with nuclear family are 3.49 times AOR: $3.49,95 \%$ Cl: 3.49 (1.09-11.12) more likely to be timely initiated breast feeding than those who live with extended families. Mothers who were delivered vaginally were 4.67 times more likely AOR: $4.67,95 \% \mathrm{Cl}:(1.92-11.33)$ to initiate their child breast feed within an hour than those who were delivered by cesarean section. Likewise mothers who counseled about timely initiation of breast feeding within an hour during ANC were 4.76 times AOR: 4.76, 95\% Cl (2.06-10.98) more likely to initiate their child breast feeding within an hour than those mothers who were not counseled about timely initiation of breast feeding during ANC visits

Conclusion : The finding of this study showed that prevalence timely initiation of breast feeding was relatively good. Keywords : timely initiation of breastfeeding, infants from birth to 12 months, Wolaita Sodo City, Ethiopia.

\section{Introduction}

Providing breast milk is a fundamental for child health because it has a straight inspiration on the comprehensive people whole quality of health and death levels. As well as being the main foundation of appropriate nourishment for breastfed babies, breast milk delivers well-known short-term paybacks in reducing the danger of death and transmittable illnesses. Likewise, breastfed infants have a lesser chance of contracting hypersensitive diseases and a lesser threat of suffering unexpected infant death syndrome. Previous studies have also established the long-term protection of breastfeeding offers against non- communicable diseases(1-3). World Health Organization (WHO) endorses that breastfeeding should be began within the first hours

Of life and exclusive breastfeeding for the first six months of infant life and continuation of breastfeeding up to two years (4). Timely initiation of breastfeeding is well-defined as placing the newborn to the 
human milk within 1 hour of birth(5) and therefore imperative for both the mother and the child. The first breast milk comprises colostrum, which is extremely nutritive and has antibodies that shield the newborn from diseases. Early initiation of breastfeeding also boosts attachment between the mother and her newborn, and accelerates the production of consistent breast milk. Timely initiation of breastfeeding can also help to avoid neonatal deaths caused by infections such as sepsis pneumonia, and diarrhea. Studies showed that when breastfeeding was initiated within the first hour, around $22 \%$ of neonatal death could be prevented(6).

In 2016, the Ministry of Health (MoH) of Ethiopia established the National Nutrition Program II (NNP II) and the National Guideline on Adolescent, Maternal, Infant, and Young Child Nutrition (AMIYCN) (FDRE 2106 b) to promote optimal feeding and care practices that follow international recommendations(7). Since then, different interventions like breast feeding promotions have been given at health institutions and at the community level by community health extension workers and other health care providers. However, these efforts are not based on systematic evidence on the level of existing practice which might be due to the paucity of data from studies on timely initiation. So timely initiation of the human milk is not solitary the simplest, cost effective and most efficacious action; it also tops the table of life-saving interventions for the well- being of the newborn $(8,9,10)$. Therefore, this study was aimed the prevalence of timely initiation of breastfeeding and associated factors among mothers with children age less than 12 months in Wolaita Sodo City, Ethiopia.

\section{Methods}

\section{Study setting and design}

The study was carried out in Wolaita Sodo city. The city has a total population of 250521. Male 79871 (52\%), female 73650 (48\%) and the city has three sub cities , 24 kebeles, three health centers, one hospital owned by $\mathrm{MOH}$ and one private hospital. The city is located from $327 \mathrm{~km}$ from Addis Ababa, the capital of Ethiopia (11). A Community based cross-sectional study design was employed.

\section{Source population}

All mothers with children less than 12 months of age in Wolaita Sodo city

\section{Study population}

Selected mothers who have a child less than 12 months of age

\section{Inclusion and exclusion criteria}

Mothers who have a child less 12 months of age, resided study area for at least six months and provided informed consent were included in the study and mothers who were seriously ill and were not volunteer 
to participate in the study were excluded.

\section{Sample size and sampling procedure}

Sample size was calculated with open- Epi statistical software version 3.03 using single population proportion statistical formulas. $n=Z(1.96) 2 P(1-P) / d ~ 2$

With assumption of: $z=1.96$, at $95 \%$ confidence level.

P-prevalence of timely initiation of breast feeding $62.6 \%$ from previous study (12).

Non-respondent rate $10 \%$ and confidence levels of $95 \%$ and $5 \%$ margin of error.

Therefore a calculated sample size was 396.

\section{Sampling procedure}

The multi stage sampling technique was used to select the study population at the community level. First 9 kebeles were selected from the total of 24 kebeles. A sample size of 396 mothers who have a child with the age less than 12 months old from each kebele were selected based on proportional allocation. The systematic random sampling technique was used to select the study unit. The households with eligible mothers and a child of less than 12 months old from each kebele were chosen from the sampled kebeles using the family folder registration book of each house hold found in the health post from health extension workers. In the households with more than one child less than 12 months, the youngest child was selected. The actual age of the infants was determined by asking the mothers and reviewing the birth date from vital certificate.

\section{Data collection procedure}

Structured, pre-tested and interviewer administered questionnaires were used. Questions on the questionnaire include the socio demographic characteristics, health service utilization, obstetrics and timely initiating of breast feeding related issues. The questionnaires were from the World Health Organization indicators for assessing infant and young child feeding practices and by adapting to the Ethiopian context. Data were collected through face-to-face interview maintaining the pre-determined sampling intervals. The data collectors informed the respondents all details of the research purpose and procedures and what was expected of them, potential risk and benefit in order to encourage accurate and honest response. When the woman was not available in the first visit, data collectors arranged alternative visits. If a woman was still not available on second visits or declined to participate in the study, the household was jumped and the immediate next household in the sampling frame was considered.

\section{Data quality management}

Before data collection the questionnaire was first prepared in English and translated into Amharic and back to English to keep the consistence of questionnaire. Two days training was given to data collectors 
and supervisors by the principal investigator before data collection.

A pretest was conducted in Areka town and $5 \%$ of total sample size was tested. Based on the pretest, questionnaires were revised, edited and the necessary corrections made accordingly. Daily check-up of data for completeness and consistency was done during data collection.

\section{Data analysis procedures}

The data entry was done using EPi-data version 3.1 and cleaned to check for accuracy, consistencies, completeness, values and any error identified was corrected.

The data was exported to SPSS version 21 software for analysis. Descriptive statistics was done. Bivariable analysis was computed and variables with p-value of less than 0.25 was made candidate for multiple logistic regression analysis. Multiple logistic regression analysis was done and variables with $\mathrm{P}$ values $\leq 0.05$ were considered as statistically significant. Adjusted Odds Ratio (AOR with $95 \%$ C.I) used to declare statistically significant association.

\section{Ethical issues}

Ethical clearance was obtained from Wolaita Sodo University Institutional Review Board (IRB). Written permission was obtained from Sodo city health office. During data collection all respondents were asked their permission and informed consent was obtained from each study participants.

\section{Operational definitions}

Based on the WHO standard (13),

Poor initiation of breast feeding: if $0-29 \%$ of mothers initiated breast feeding within one hour of delivery

Fair initiation of breast feeding: if $30-49 \%$ of mothers initiated breast feeding within one hour of delivery

- Good initiation of breast feeding: if $50-89 \%$ of mothers practiced breast feeding within one hour of delivery

- Very good initiation of breast feeding: if $90-100 \%$ of mothers practiced breast feeding within one hour of delivery

- Early initiation of breastfeeding (EIBF): refers to if a mother who put her baby to breast initiated breast feeding within one hour following delivery

\section{Result}




\section{Socio demographic and economic characteristics of the respondents}

Among 396 eligible mothers of this study, 383 mothers were agreed and participated in this study making the response rate of $97.7 \%$. The mean age of mothers participated in this study was 25.97 . A big majority $329(85.7 \%)$ of respondents were Wolaita in their ethnic group. About 262(68.4) of respondents were protestant Christian in their religious affiliation. About $147(38.4 \%)$ of mothers completed primary school and $290(75.7 \%)$ of them were house wife. Around $197(51.4 \%)$ of infants were females and $186(48.6 \%)$ of them were males in their sex. From 383 mothers, 348(90.9\%) of mothers were living with their nuclear family. The big majority of families $235(61.4 \%)$ have one under-five children. About 350(91.4\%) the study participants have exposure to mass media and majority of respondents $133(34.7 \%)$ have one thousand Ethiopian birr as monthly income of the family and almost all $381(99.5 \%)$ of the families have under-five children from one three (Table 1.)

\section{Obstetric and maternal health care service utilization characteristics}

The highest majority 367(95.7) of respondents have had received antenatal care. About 333(86.9\%) of participants started their antenatal care before fifth month of gestation. Majority of the mothers $179(46.7 \%)$ have had antennal visit of four times and $164(42.8 \%)$ of them have one to three antenatal follow ups. 249(65\%) of the study participants have had got counseling on breast feeding, from these, $215(56.1 \%)$ were receiving counseling on timely initiation of breastfeeding. 307(80.2\%) respondents delivered at health institutions and $340(88.8 \%)$ of them assisted by health care professionals. From the total of 383 mothers, $333(86.9 \%)$ of mothers had spontaneous vaginal delivery. About $176(46 \%)$ of infants were first in their birth order (Table 2).

\section{Breast feeding practice and related characteristics of mothers}

The overall breast feeding practice of the study participants for their current infant is 369(96.3\%). From the 383 mothers who were participated, 307(80.2\%) initiated feeding their infants with in one hour of delivery. About 329 (85.9\%) of respondents heard about early initiation of breast feeding, $317(82.8)$ were thinking that giving breast milk with in 1 hour of birth is important. $333(86.9 \%)$ were giving breast milk based on the demand of children (Table 3).

\section{Reasons why mothers did not give breast milk with in 1 hour after delivery}

About 34(8.9\%) out of 76 mothers did not give breast milk with in 1 hour after delivery to their infants because of maternal illness (Fig. 1)

Factors associated with timely initiation of breast feeding within an hour after birth 
The Bivariate binary logistic regression analysis yielded that sex of the child, place od delivery for the current child, mode of delivery, exposure to media, counseling given during antenatal care about timely initiation of breast feeding and family type became candidate for multiple logistic regression analysis at p.

In the final logistic regression (multivariable logistic regression analysis) model sex of the child, family type, mode delivery, counseling given during antenatal care about timely initiation were significantly associated with timely initiation of breast feeding at P-value less than 0.05 . Being male child was 3.39 times AOR: $3.39,95 \% \mathrm{Cl}: 3.39(1.49,7.71)$ more likely to be timely initiated breast feeding within an hour than those who are female children. Those children who live with nuclear family are 3.49 times AOR: 3.49, 95\% Cl: 3.49 (1.09-11.12) times more likely to be timely initiated breast feeding than those who live with extended families. Mothers who were delivered vaginally were 4.67 times more likely AOR: $4.67,95 \% \mathrm{Cl}:($ 1.92-11.33) to initiate their child breast feed within an hour than those who were delivered by cesarean section. Likewise mothers who counseled about timely initiation of breast feeding within an hour during ANC were 4.76 times AOR: $4.76,95 \% \mathrm{Cl}(2.06-10.98)$ more likely to initiate their child breast feeding within an hour than those mothers who were not counseled about timely initiation of breast feeding during ANC visits (table 4 ).

\section{Discussion}

Timely initiation of breastfeeding is fundamental for existence of neonates; therefore this particular study was aimed to estimate the prevalence of timely initiation of breast feeding. Despite its importance, the practice of timely initiation of breasting feeding is not adequate in the study area. Only $80.2 \%$ of mothers practiced early initiation of breasting which is below the level planned to achieve by Ethiopian health sector development (HSDPIV) by 2015 to the target of $92 \%$ (7). The finding from the current study is generally good but lower than WHO recommendation on young infant and child feeding rate on early initiation of breastfeeding to be very good $(90-100 \%)(13)$. The result of the recent study is comparable with study done in Dembecha district 73.1\%(14) in Bahir Dar City 75.4 \% (15), in Debre Tabor Town 76.8 \%(16), in Motta Town $78.8 \%(17)$, in Nambia $74.9 \%(18)$ and in Zimbabwe(19) 78 \%. But finding of this study is higher than the study conducted in Debre Brehan Town 62.6 \% (12), in North West Ethiopia 53.3 \% (20), in South Sudan 48 \% (21) Middle East 34.3 \%(22), and lower than the study done in Kassala, Eastern Sudan $87.2 \%$ (23). The variance between the present study others may be because of maternal socio-demographic and economic features like i.e. access to information, socio-economic status, infrastructure, educational status, cross cultural changes in breastfeeding practice, and health service utilization individualities.

The finding of the current study showed that children living with nuclear family were 3.49 times more likely to be timely initiated breast feeding than those children living with extended family. This finding is consistent with study conducted in Debre Birhan town, Northwest Ethiopia, which showed that having extended family is negatively associated with timely initiation of breast feeding (12). This is because 
children who live with nuclear family have high support for the mother to initiate her child breast feed after delivery.

Modes of delivery were significantly associated with timely initiation of breastfeeding. A mother who gave birth via vaginal delivery was 6.67 times more likely to initiate breastfeeding within one hour than those gave birth via cesarean section. This finding is in line with studies done in Bahiradr (15) and Motta (17) . This may be due to recovery for the mother after cesarean which make it difficult to initiate breastfeeding early.

The current study showed that mothers who were counseled during antenatal visits were 4.67 times more likely to initiate timely breastfeeding than those who were not counseled during antenatal visits. This finding is consistent with studies done in Ethiopia; Bahiradr (15) and Motta (17) This may be due to mothers who had antenatal visits receive enough information about the importance of early initiation of breastfeeding and have also adequate knowledge about breastfeeding, which may lead to early initiation of breastfeeding compared to women who were not counseled.

This study revealed that being male child is 3.39 more likely to be timely initiated breast feeding within an hour than being female child. This finding is consistent with other study conducted in Goba ,Ethiopia which showed that being male child was 1.85 times more likely to be timely initiated than being female child (24).

This study revealed that place of delivery was not significantly associated with timely initiation of breastfeeding practices. This finding is inconsistent with study conducted in Debre Birhan (12) ,Bahiradr (15), and Motta (17),

\section{Limitation Of The Study}

This study was conducted in urban community, Sodo city which may not equally represent the rural community and also in this study causal conclusions cannot be drawn.

\section{Conclusion And Recommendation}

The overall breast feeding practice of the study participants for their current infant is $369(96.3 \%)$ and Prevalence of timely initiation of breast feeding within an hour was $80.2 \%$ which is good based on WHO standard but below its recommendation. Being male child, living with nuclear family, vaginal delivery and counseling about timely initiation of breast feeding within an hour during ANC were factors associated with timely initiation of breast feeding within an hour. Therefore, based on the findings of the study we recommend: health professionals have to provide health education on timely initiation of breast feeding during ANC follow up. In addition mass media should advocate timely initiation of breast feeding and its advantages. Health Extension Workers should also educate the community advantages of timely initiation of breast feeding at the community level. 


\section{Abbreviations (Acronyms And Abbreviations)}

AMIYCN...Adolescent, maternal, infant and young child nutrition, AOR... Adjusted Odds Ratio, Cl... Confidence interval, EDHS... Ethiopian Demographic health survey, ElBF...Early initiation of breastfeeding, FDRE...Federal democratic republic of Ethiopia, HSDPIV.... Health sector development plan four, LMICs ... Low and middle income countries, $\mathrm{MoH}$....Ministry of Health $\mathrm{MoH}, \mathrm{NNPII......National} \mathrm{Nutrition} \mathrm{Program}$ two ,SSA...Sub Saharan Africa, UNICEF ......United Nations international children education fund, WHO ... World health organization

\section{Declarations}

\section{Acknowledgment}

We would like to forward our gratitude to Wolaita Sodo University, College of Health Sciences and Medicine. We also thank Wolaita Zone administrators, the supervisors, respondents and data collectors.

\section{Authors' contribution}

$\mathrm{DB}, \mathrm{KTB}$, and TL

These authors equally contributed to this research work

\section{Funding}

This study is not funded

\section{Availability of data \& materials}

The data for this research is available, so we can contact you when you need our data for the future process.

\section{Ethics approval and consent to participate}

Ethical clearance and approval letter to conduct study was obtained from Wolaita Sodo University institutional review board and a letter of cooperation was taken from the Wolaita Sodo University College of health science and Medicine to Wolaita Sodo city health bureau. Written consent was obtained from the study participants after explaining the study objectives and procedures and their right to refuse not to participate in the study any time they want was assured. For this very purpose, a one page consent letter was attached to the cover page of each questionnaire stating about the general objective of the study and issues of confidentiality which was discussed by the data collectors before proceeding with the interview. Confidentiality of the information was ensured by coding. The interview was undertaken 
privately in separate area. Only authorized person was getting access to the raw data collected from the field.

\section{Consent for publication}

Not applicable

\section{Competing interests}

The authors have declared that no competing interests exist.

\section{References}

1. Ip S, Chung M, Raman G, et al. Breastfeeding and maternal and infant health outcomes in developed countries. Evid Rep Technol Asses. 2007; 153:1-186..

2. Kwan ML, Buffler PA, Abrams B, Kiley VA. Breastfeeding and the risk of childhood leukemia: a metaanalysis. Public Health Rep. 2004; 119:521-535.

3. Sadauskaite-Kuehne V, Ludvigsson J, Padaiga Z, Jasinskiene E, Samuelsson U. Longer breastfeeding is an independent protective factor against development of type 1 diabetes mellitus in childhood. Diabetes Metab Res Rev. 2004;20:150-157

4. WHO. Exclusive breastfeeding for Six months best for babies. Geneva: WHO; 2011.

5. World Health Organization, UNICEF. Indicators for assessing infant and young child feeding practices part 3: country profiles. Geneva: WHO available ahttp://apps.who.int/iris/bitstream/10665/44368/1/9789241599757_eng.pdf; 2010.

6. Edmond KM, Zandoh C, Quigley MA, Amenga-Etego S, Owusu-Agyei S,Kirkwood BR. Delayed breastfeeding initiation increases risk of neonatalmortality. Pediatrics. 2006;117(3):e380-6.

7. Federal Democratic Republic of Ethiopia Ministry of Health. Health Sector Development Program IV, 2010/11-2014/15, https://www. healthynewbornnetwork.org/resource/federal-democratic-republicethiopiaministry- health-health-.

8. World Health Organization (WHO): The optimal duration of exclusive breastfeeding: Report of an expert consultation. Department of nutrition for health and development and department of child and adolescent health and development. Geneva, Switzerland; 2001.

9. Koosha A, Hashemifesharaki R, Mousavinasab N: Breast-feeding patterns and factors determining exclusive breast-feeding. Singapore Med J 2008, 49(12):1002-006.. 
10. Du Plessis D: Breastfeeding: Mothers and health practitioners, in the context of private medical care in Gauteng. Journal of Interdisciplinary Health Sciences 2009, 14(1).

11. Wolaita Zone Finance, Socio Economic and Population report, 2017/2018 p 49.

12. Tilahun G, Degu G, Azale T, Tigabu A. Prevalence and associated factors of timely initiation of breastfeeding among mothers at Debre Berhan town, Ethiopia: a cross-sectional study. Int Breastfeed J. 2016;11:27.

13. World Health Organization. Infant and young child feeding: a tool for assessing national practices, policies and programmes. http://www.who.int/nutrition/publications/ infantfeeding/9241562544/en/. Published 2003.

14. Bimerew A, Teshome M, Kassa GM. Prevalence of timely breastfeeding initiation and associated factors in Dembecha district, North West Ethiopia: a cross-sectional study. Int Breastfeed J. 2016;11:28.

15. Belachew A. Timely initiation of breastfeeding and associated factors among mothers of infants age 0-6months old in Bahir Dar City, Northwest, Ethiopia, 2017: a community based cross-sectional study. International Breastfeeding Journal (2019) 14:5 https://doi.org/10.1186/s13006-018-0196-3

16. AaG. Early initiation of breastfeeding and colostrum feeding among mothers of children aged less than 24 months in Debre Tabor, northwest Ethiopia: a cross-sectional study. BMC Research Notes. 2019;12(65).

17. Tewabe. Timely initiation of breastfeeding and associated factors among mothers in Motta town, East Gojjam zone, Amhara regional state, Ethiopia, 2015: a cross-sectional study. BMC Pregnancy and Childbirth. 2016;16.

18. al. N. Trends and factors associated with earlyinitiation of breastfeeding in Namibia:analysis of the Demographic and HealthSurveys 2000-2013. BMC Pregnancy and Childbirth https://doiorg/101186/s12884-018-1811-4. 2018;18(171).

19. al. M-Me. Predictors of early initiation of breastfeeding among Zimbabwean women: secondary analysis of ZDHS 2015. BMC. 2019;5(2).

20. al. Te. Only half of the mothers practiced early initiation of breastfeeding in Northwest Ethiopia, 2015. BMC Research Notes. 2017;10.

21. Bruno Tongun et al. Factors associated with delayed initiation of breastfeeding: a cross-sectional study in South Sudan. International Breastfeeding Journal. (2018) 13:28

22. Alzaheb RA. A Review of the Factors Associated With the Timely Initiation of Breastfeeding and Exclusive Breastfeeding in the Middle East. Clinical Medicine Insights. 2017;11:1-15.

23. al. H. Assessment of initiation of breastfeeding practice in Kassala, Eastern Sudan: a communitybased study. Int Breastfeed J. 13(34).

24. Setegn T, Gerbaba M, Belachew T. Determinants of timely initiation of breastfeeding among mothers in Goba Woreda, South East Ethiopia: a cross sectional study. BMC Public Health. 2011;11:217. 
25. Joshi et al. Prevalence of exclusive breastfeeding and associated factors among mothers in rural Bangladesh: a cross-sectional study. International Breastfeeding Journal 2014, 9:7 .

\section{Tables}

Table 1: Socio-demographic and economic characteristics of the respondents (mothers) among mothers of infants less than 12 months of age in Wolaita Sodo City, Wolaita, Ethiopia 2019 


\begin{tabular}{|c|c|c|}
\hline variables & Category $(n=383)$ & Frequency (\%) \\
\hline \multirow[t]{5}{*}{ Age of the mother } & $<19$ & $26(6.8)$ \\
\hline & $20-24$ & $181(47.3)$ \\
\hline & $25-29$ & $109(28.5)$ \\
\hline & $30-34$ & $46(12)$ \\
\hline & 35 and above & $21(5.5)$ \\
\hline \multirow[t]{4}{*}{ Ethnicity } & Wolaita & $329(85.7)$ \\
\hline & Amhara & $22(5.7)$ \\
\hline & Gurage & 19(5) \\
\hline & others & $13(3.4)$ \\
\hline \multirow[t]{3}{*}{ Marital status of mother } & Married & $359(93.7)$ \\
\hline & Divorced & $16(4.2)$ \\
\hline & Widowed & $8(2.1)$ \\
\hline \multirow[t]{4}{*}{ Religious affiliation } & Protestant & $262(68.4)$ \\
\hline & Orthodox & $95(24.8)$ \\
\hline & Muslim & $21(5.5)$ \\
\hline & others & $5(1.3)$ \\
\hline \multirow[t]{4}{*}{ Maternal educational level } & Illiterate & $19(5)$ \\
\hline & Completed primary & $147(38.4)$ \\
\hline & Competed secondary & $132(34.5)$ \\
\hline & College and above & $85(22.2)$ \\
\hline \multirow[t]{2}{*}{ Occupational status of mother } & House wife & $290(75.7)$ \\
\hline & employed & $33(24.3)$ \\
\hline \multirow[t]{5}{*}{ Husbands educational status } & Illiterate & $17(4.4)$ \\
\hline & Primary level & $92(20)$ \\
\hline & High school & $130(33.9)$ \\
\hline & College and above & $120(31.3)$ \\
\hline & Others(divorced and widowed) & $24(6.3)$ \\
\hline \multirow[t]{3}{*}{ Occupational status of husband } & Employed & $207(54)$ \\
\hline & Unemployed & $152(39.7)$ \\
\hline & Others(divorced and widowed) & $24(6.3)$ \\
\hline
\end{tabular}

Page 13/17 


\begin{tabular}{|c|c|c|}
\hline \multirow[t]{2}{*}{ Sex of infant } & Male & $186(48.6)$ \\
\hline & female & $197(51.4)$ \\
\hline \multirow[t]{2}{*}{ Age of infant } & Birth to 6 months & $187(48.8)$ \\
\hline & 7 to 11 months & 196(51.2) \\
\hline \multirow[t]{2}{*}{ Family type } & Nuclear & $348(90.9)$ \\
\hline & Extended & $35(9.1)$ \\
\hline \multirow[t]{2}{*}{ Number of under-five children } & Less than 3 & $381(99.5 \%)$ \\
\hline & 4 and above & $2(0.5 \%)$ \\
\hline \multirow[t]{2}{*}{ Exposure to mass media } & Exposed & $350(91.4)$ \\
\hline & Not exposed & $33(8.6)$ \\
\hline \multirow[t]{4}{*}{ Monthly income } & Less than 1500 & $133(34.7)$ \\
\hline & 1501 to 3000 & $94(24.5)$ \\
\hline & 3001 to 4500 & $92(24)$ \\
\hline & 4501 and above & $64(16.7)$ \\
\hline
\end{tabular}

Table 2: Obstetric and health care service utilization among mothers with infants from birth to 12 months of age in Wolaita Sodo City, Wolaita, Ethiopia 2019 


\begin{tabular}{|c|c|c|}
\hline Variables & Categories or responses & Frequency (\%) \\
\hline \multirow[t]{2}{*}{ Antenatal visits } & Yes & $367(95.8)$ \\
\hline & No & 16(4.2) \\
\hline \multirow[t]{2}{*}{ Gestational age of first antenatal visits $(n=367)$} & Before $5^{\text {th }}$ month & 333(86.9) \\
\hline & After $5^{\text {th }}$ month & $34(8.9)$ \\
\hline \multirow[t]{3}{*}{ Number of antenatal visits(367) } & 1 & $19(5.2)$ \\
\hline & $2-3$ & $145(37.8)$ \\
\hline & 4 and above & 203(53.00) \\
\hline \multirow[t]{2}{*}{ Counseling on breast feeding during antenatal care $(n=367)$} & Yes & $249(65)$ \\
\hline & No & 118(30.8) \\
\hline \multirow[t]{2}{*}{ Counseling on timely initiation of breastfeeding during antenatal care $(\mathrm{n}=367)$} & Yes & $215(56.1)$ \\
\hline & No & $35(9.1)$ \\
\hline \multirow[t]{2}{*}{ Place of delivery $(n=383)$} & Health institution & $307(80.2)$ \\
\hline & Home & 76(19.8) \\
\hline \multirow[t]{3}{*}{ Birth attendants $(\mathrm{n}=383)$} & Health care workers & $339(88.5)$ \\
\hline & Family & $27(7.0)$ \\
\hline & Traditional attendants & $17(4)$ \\
\hline \multirow[t]{3}{*}{ Mode of delivery $(\mathrm{n}=383)$} & Spontaneous vaginal delivery & 333(86.9) \\
\hline & Caesarean section & \\
\hline & & $50(13.1)$ \\
\hline \multirow[t]{3}{*}{ Infants birth order } & First & $176(46)$ \\
\hline & Second & $118(30.8)$ \\
\hline & Third and above & $89(23.2)$ \\
\hline
\end{tabular}

Table 3: Breast feeding practice of mothers with infants from birth to 12 months of age in Wolaita Sodo City, Wolaita, Ethiopia 2019 


\begin{tabular}{|l|l|l|}
\hline Variables & responses & Frequency (\%) \\
\hline Breast feeding current child & Yes & $369(96.3)$ \\
& No & $14(3.7)$ \\
\hline Breastfed with in 1 hour of delivery & Yes & $307(80.2)$ \\
& No & $76(19.8)$ \\
\hline Heard about timely initiation of breast feeding & Yes & $329(85.9)$ \\
& No & $54(14.1)$ \\
\hline Think early initiation of breast feeding is important & Yes & $317(82.8)$ \\
\hline Fed other than breast milk with in 1 hour of birth & Yes & No \\
\hline Feeding based on demand of infant & No & $305(79.6)$ \\
\hline
\end{tabular}

Table 4: - Factors affecting timely in initiation of breast feeding among mothers with children age less than 12 months, 2019.

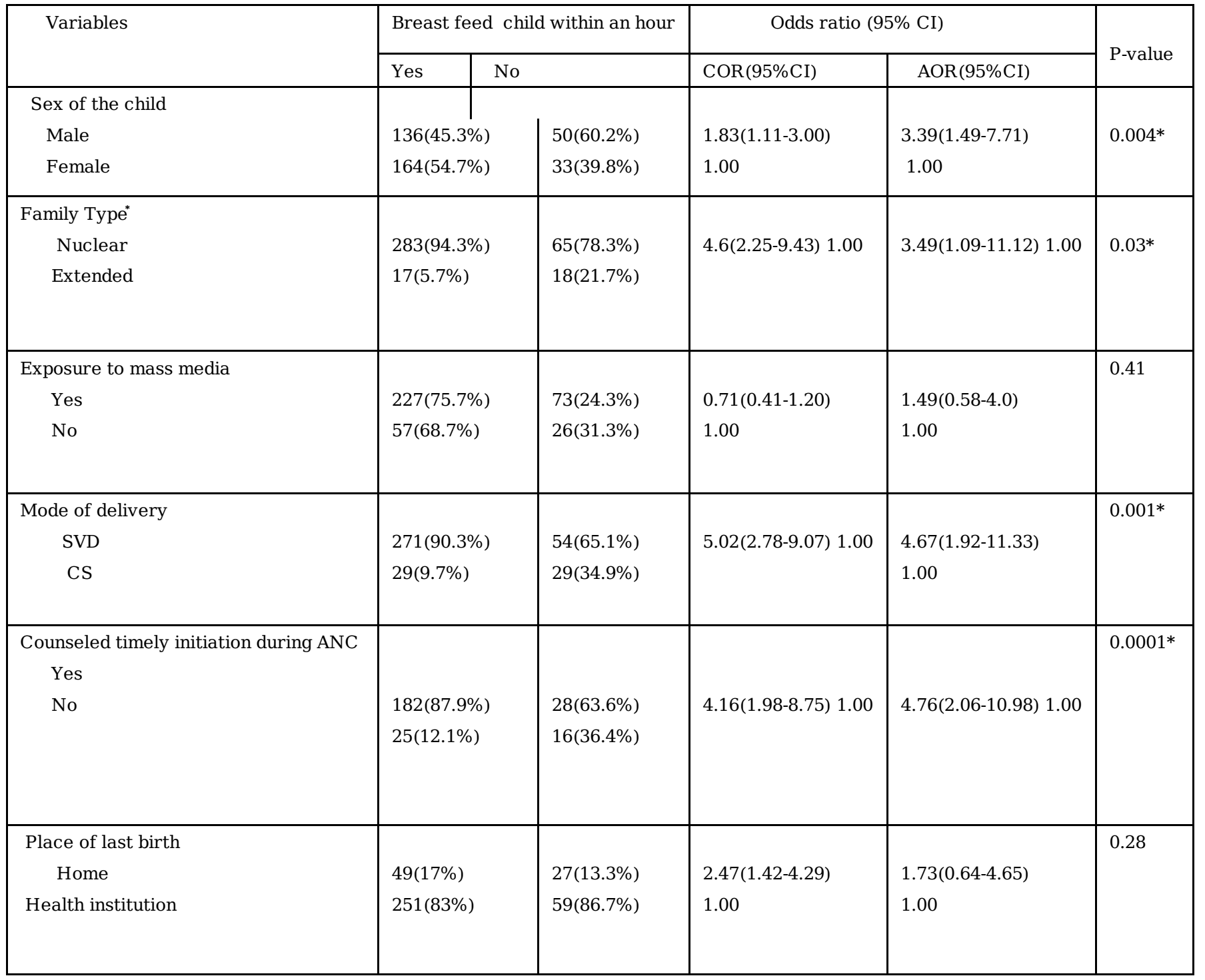


Figures

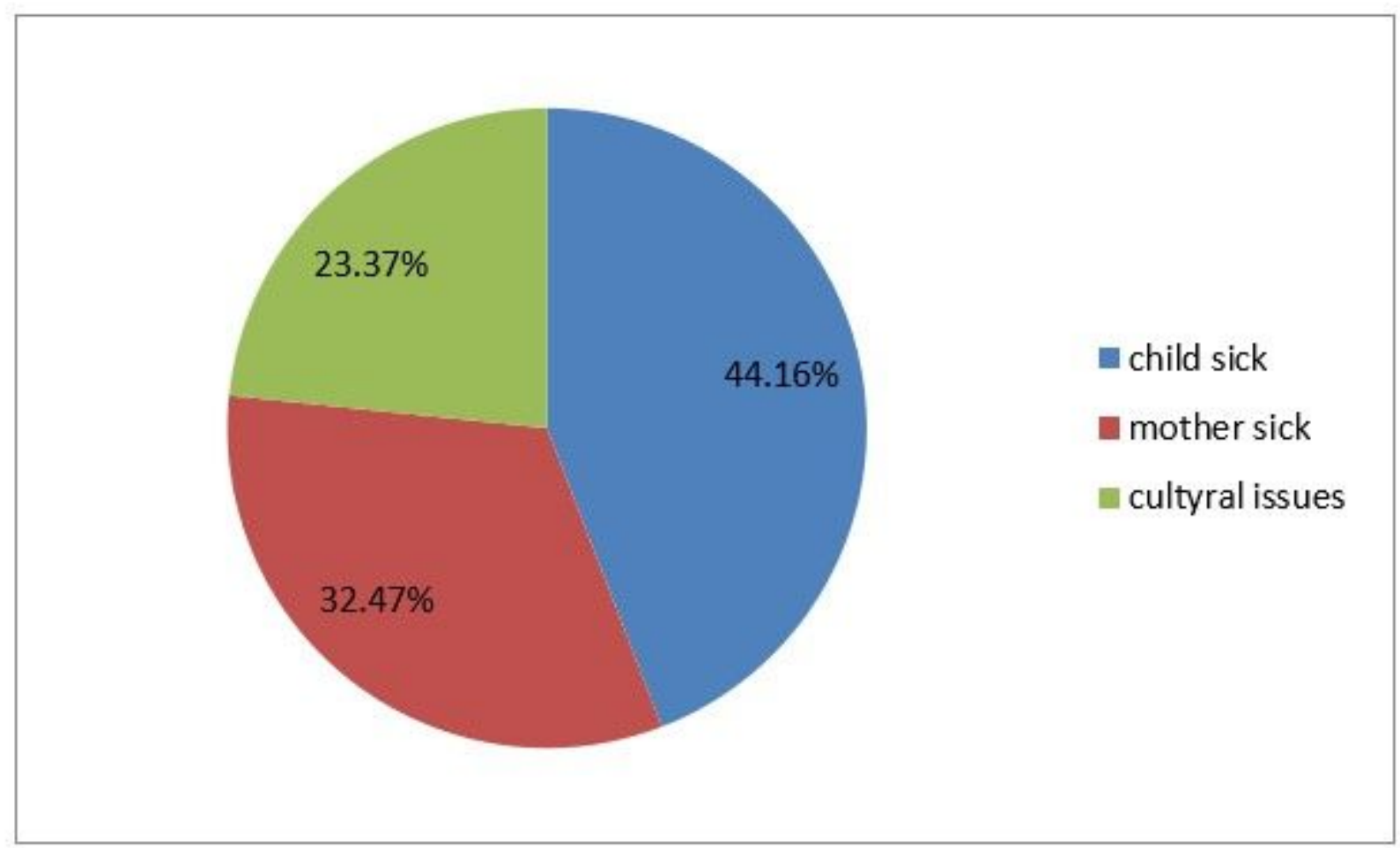

Figure 1

Reasons why mothers did not give breast 